DOI: $10.51480 / 1899-5101.14 .1(28) .12$

\title{
DMITRY CHERNOBROV (2020). PUBLIC PERCEPTION OF INTERNATIONAL CRISES IDENTITY, ONTOLOGICAL SECURITY AND SELF-AFFIRMATION. LANHAM: ROWMAN \& LITTLEFIELD PUBLISHERS, 256 PP., ISBN: 978-1786610034.
}

With his book Public Perception of International Crises Identity, Ontological Security and Self-Affirmation, Dmitry Chernobrov tries to show the relationships between crisis, social movement, national identity, and the public perception. The author has attempted to present the particular case of the Arab uprising thatstarted in 2010in order to research public perception of the meaningful event. The subject matter and the presented problems were characterized and discussed in a very original way.

The author compares Russians and Britons in the context of each nation's perception of the Arab uprising. The UK and Russia, two countries with imperial histories, are treated by the author as examples of Western and Russian identity. Chernobrov emphasizes the mass media's shaping of public perception as the main information for the communities and individuals. The book includes empirical layers as well, as the author compares data from 51 semi-structured interviews with citizens of the UK and Russia.

In his introduction (p. 4), Chernobrov says:

\begin{abstract}
"Collective identities - or the communities of people united by the subjective sense of common belonging and inner imagining are central to public perception of international events. Making sense of complex international crises is a process in which self and other identities are constructed, and multiple others become idealised, repelled, accepted, or rejected. Vast literature has illustrated how self-identity develops through contrast with otherness, making both self and other present in the representations of the international. Identities are an inherent part of describing international events and their agents, while news about these events is received in complex social contexts".
\end{abstract}

The book comprises three parts. The first, "The Drawing Self," starts with the chapter "Perception and Collective Identity." In this chapter, theauthor tries to establish a link between collective identity and perception. Chernobrov says that the term "international" has been related to the contexts of states, nation structures, elites, or groups of interest, but is rarely related to individuals. 
Moreover, he analyzes identity formation in external and internal understandings. In Chernobrov's opinion, the perception of what constitutes 'international' and 'individual' is always involved in communication in a social context. The media are the main information source about international events for most citizens, responsible for agenda setting and interpretation of international events. The author points out that beliefs, opinions, and behaviors are not only personal, but social as well. An individual is created by a collective, as Chernobrov indicates.

In chapter two, "Anxiety of the Unknown and (Mis)Recognition," the author describes several aspects of the problem of security, demonstrating that security as an identity is still an incomplete project. The author presents ontological security theory, the idea that unexpected events like a crisis can destabilize a community. The anxiety of the unknown can trigger a sense of uncertainty, upset identity, and interrupt the sense of continuity. Such events involve a self-defense mechanism. The (mis)recognizing gives an illusion of knowing or recognizing unexpected events. The communities maintain self-conceptions and meanings as sources of security and empowerment to protect the continuity in the international affairs aspects as well.

In chapter three, the author focuses on the phenomenon of self-drawing, the term Chernobrov understands as a constant renegotiating of the identity in the context of internal and external sources. Individuals strive for security; however, this security can be narcissistic. As Chernobrov observes: "Narcissistic security is dubious as it is likely to cause aggressive responses and self-affirmations, and to damage the physical and identity security in the long run" (p. 75). This chapter closes the first part of the book, which is devoted to the links between the anxiety of the unknown and the protections of positive self-conceptions.

Chernobrov focuses on the problem of perception of others in the second part of the book. In the fourth chapter, he analyzes what it means to be similar or different, noticing that difference is often associated with negative attitudes. Dialogue and mutual reconciliation can be an antidote. The language of difference and hierarchy is especially crucial. The author considerers the relationships between sympathy/antipathy and similarity/difference, underlining the importance and need to discuss these issues.

In chapter five, the author discusses how events are constructed in community memory, which he terms "collective memory." The collective memory plays a key aspect in constructing the self-conceptions of communities, characterized by selective memory and the image of the crisis. Chernobrov (p. 145) also notes:

"Chosen memories become chosen for the usability and inner significance they can offer for identity construction and the reduction of anxiety. Remembering creates a boundary between selves and others, while forgetting can prevent the 
self from perceiving the other for what it is, outside the self's own troubling past and the need to revisit and reconcile with".

The third part of the book is empirical. In the sixth chapter, Chernobrov focuses on the public perception of international crises. The author is interested in public perception in Russia and the UK of the Arab Spring, particularly related to Libya and Syria. His goal is to compare opinion about the uprising through similar (un)conscious mechanisms among the general public of two nations. The author analyzes 51 semi-structured in-depth interviews of Britons and Russians about their understanding of the Arab Spring in Libya and Syria. The study took place in 2012-2013. The author explains the field of research (p. 152):

"The choice of Russia and the UK was also driven by considerations of effective linguistic and cultural interpretation: interviews were conducted directly in English in the UK and in Russian in Moscow. Interviewees were British and Russian nationals respectively, shared a common national and cultural identity, and were primarily following their national media".

A discussion about qualitative research has always been as challenging, the researcher is torn between the lack of objectivity and the comprehensiveness of qualitative studies. In my opinion, qualitative research can be treated as a worthy contribution to the academic discourse. The main advantage is the depth of research because objectivity is less important. The findings of the research presented by Chernobrov gives the reader compelling conclusions about two nations. However, we must remember that these conclusions are rather an impetus for further studies. Most Britons described the uprising as a Western-inspired struggle of democracy against oppression, while most Russians saw the event as a dangerous destabilization. The attitudes and opinions expressed by those interviewed are characteristic of their own sense of identity related to opinions disseminated among nations, both familiar and troubling experiences.

Chapter seven comprises the study of the wider societal, political, and media narratives concerning the Arab Spring in Russia and the UK. Chernobrov notes that the UK is representative of the West. It is worth quoting (p. 10):

"I witness the construction and the gradual downfall of the 'good rebel' in British public discourse as a Westerner fighting for democracy in an Arab street. In Russia, the political and media representations evolved from (mis)-recognising the first uprisings as familiar economic crises to explaining themas a rejection of stability forced by Western strategic interference". 
In my opinion, Chernobrov's book is a valuable contribution to the discussion about national crisis perception. The conclusions about the national identity, public opinion, opinion leaders, and the media's function in public perception of international events seem to me particularly crucial. The advantage of this book is its attempt to show two perspectives of the same event-Russian and Western. The qualitative study analyzing public perception is the best tool to achieve a comprehensive outcome.

Agnieszka Weglińska UNIVERSITY OF LOWER SILESIA, POLAND 